\title{
Governance, enabling frameworks and policies for the transfer and diffusion of low carbon and climate adaptation technologies in developing countries
}

\author{
James Haselip $^{1}$ • Ulrich Elmer Hansen ${ }^{1}$ • Daniel Puig ${ }^{1}$ • \\ Sara Træup ${ }^{1} \cdot$ Subash Dhar ${ }^{1}$
}

Received: 17 October 2014 / Accepted: 13 May 2015 / Published online: 8 June 2015

(C) Springer Science+Business Media Dordrecht 2015

\section{Introduction}

Technologies are available to curb the causes and impacts of climate change. Efforts to scale up the development, transfer and diffusion of these technologies to and within developing countries are gaining momentum, with the United Nations Framework Convention on Climate Change (UNFCCC) spearheading international initiatives in this area. Indeed, technology transfer for climate change has long been recognised as a priority issue within the UNFCCC (UNFCCC 1992). Commitments to promote technology transfer to developing countries have been renewed at every Conference of Parties (COP) to the Convention (most notably in Article 10c of the Kyoto Protocol, in the subsequent Marrakesh Accords and, more recently, with the Poznan Strategic Programme on Technology Transfer agreed at COP-14, in 2008). In 2010 this level of commitment led to the establishment of the so-called Technology Mechanism, which aims to 'facilitate enhanced action' on technology development and transfer to support progress on climate change mitigation and adaptation. Related to this are numerous ongoing initiatives in developing countries, including Technology Needs Assessments (TNAs), Low Carbon Development Strategies and Nationally Appropriate Mitigation Actions (NAMAs), financed by bilateral and multilateral organisations as well as, in some cases, developing country budgets.

While technology transfer is high on the UNFCCC agenda, it is also a highly contested and controversial issue within international climate politics. Discussions about technology transfer to developing countries are often polarised along a north-south divide, which is historically rooted in political negotiations under various global environmental agreements (Roberts and

This article is part of a Special Issue on "Governance, enabling frameworks and policies for the transfer and diffusion of low carbon and climate adaptation technologies in developing countries" edited by Subash Dhar, Ulrich Hansen, James Haselip, Daniel Puig, and Sara Trærup

James Haselip

jhas@dtu.dk 
Parks 2006). The 'southern' perspective generally stresses that, since developed countries are primarily responsible for causing climate change, developing countries should not make commitments to reduce greenhouse gases, which could slow down economic development, without compensation (Haum 2011). In short, developing countries have identified technology transfer as a precondition for furthering adaptation to, and (in particular) mitigation of, climate change, while arguing that promises made by developed countries to enhance technology transfer have not been met. Meanwhile the 'northern' perspective maintains that since greenhouse gas emissions from developing countries are now greater than those of developed countries, developing countries should take on a greater responsibility to help mitigate climate change, using mostly modern technologies imported from developed countries.

Notwithstanding these controversies, the political discussion on technology transfer under the UNFCCC is characterised by a highly narrow and instrumentalist (and sometimes even naïve) understanding of technology, and the conditions under which technology transfer occurs. This is reflected in the widespread preoccupation with the tangible aspects of technology as a piece of material equipment and machinery that can lead to a (net) reduction in greenhouse gas emissions (Ockwell and Mallett 2012). This narrow understanding of technology as hardware has led to a predominant focus in policy discussions on the physical relocation and deployment of technical components across space as a one-off, discrete event in time (Byrne et al. 2012). The orientation towards the tangible aspects of technology as codified information (embodied for example in technical design specifications) is also reflected in the much-debated issue of intellectual property rights (IPR) within negotiations under the UNFCCC (Ockwell et al. 2010).

In addition, international climate change negotiations have been shaped by, or rather reflect, the wider political-economic context where neoliberal (pro-market) ideas and arguments have become an accepted 'common sense' over the last 25 years. In this process, such free-market doctrines and practices have evolved from an overtly political project to an increasingly technocratic agenda (Haselip 2010; Peck 2004; Peck and Tickell 2002). This 'technocratic neoliberalism' has pervaded the UNFCCC, where its appeal (real and justified, or perceived and unjustified) has co-opted many erstwhile critics, thus marginalising serious debate over the validity of markets as a means to achieve meaningful greenhouse gas emission reductions.

Against this background the use of market-based mechanisms has been presented as an alternative to more traditional 'command and control' approaches, such as direct legislation, to governing the problem of climate change. Legislation was effective in mitigating chlorofluorocarbon compounds under the Montreal Protocol and, while climate change is a fundamentally more complex problem compared to ozone layer depletion, involving a far wider range of sectors and technologies, there is a case to be made for reconsidering whether the international community should rely more strongly on 'command and control' approaches to manage climate change.

However, agreeing and enforcing such non-market based approaches, for example in the form of government-imposed limits on the production and use of fossil fuels, poses a serious economic threat to corporate actors across a wide range of industries (Levy and Egan, 2003), who have formidable lobbying powers. This makes the challenge of reducing GHG emissions though direct legislation politically far harder in the face of significant resistance from multinational industries, compared to market-based approaches.compared to market-based approaches. Instead, the Kyoto Protocol's flexible mechanisms, which are market-based instruments, have become a flagship UNFCCC tool for regulating global greenhouse gas emission reduction efforts. In combination with the predominant technological hardware focus, this market orientation has reduced discussions about technology transfer mainly to a question of getting the economic incentives right. The combination of these two 
predominant market and technology hardware discourses is perhaps most clearly discernible in the Clean Development Mechanism (CDM) of the Kyoto Protocol, which Ockwell and Mallett (2012) have called a 'hardware financing mechanism'. As will be pointed out below, this discourse has a number of shortcomings concerning the understanding of governance, enabling frameworks and policies related to the transfer and diffusion of climate technologies.

The academic literature on technology transfer in the context of climate change is still limited and the studies undertaken have been relatively narrow in their scope and focus. Most of the literature has analysed the extent to which CDM projects contribute to promote technology transfer to developing countries, based on statements in project documents (Haites et al. 2006; Dechezleprêtre et al. 2007, 2008; de Coninck et al. 2007; Schneider et al. 2008; Seres et al. 2009; Das 2011; Haščič and Johnstone 2011; Murphy et al. 2013). Lema and Lema (2013) criticises these studies for only addressing whether technology transfer occurs instead of exploring the more interesting question of how it occurs (if and when it does). In addition, these studies focus mostly on hardware transfer and where the intangible aspects of technology are analysed, this is often through a binary distinction between hardware and knowledge, which Bell (2012) criticises as being overly reductionist. A smaller body of literature has studied patents as a measure of international technology transfer (Dechezleprêtre et al. 2011, 2013; De la Tour et al. 2011). However, these studies not only suffer from a preoccupation mainly with the tangible aspects of technologies, but also from a narrow emphasis on one particular element of the enabling framework for technology transfer (Pueyo 2013).

In summary, due to the prevailing hardware and market discourses in the policy arena, which has spilled over into academic research, it is clear that a number of outstanding gaps remain in our understanding of the conditions under which technology transfer take place. Given the tendency to consider technology transfer as a one-off event, there is a limited understanding of how technology transfer, as an external intervention, connects with ongoing internal processes and institutional conditions at the national and local level. Addressing this knowledge gap would involve greater attention to the nature of the 'embeddedness' of technologies within the specific organisational, institutional, political and natural resource conditions through which the technologies diffuse (Desgain and Haselip 2015). By focusing on the context-specific factors and governance aspects of technology transfer and diffusion, we can divert attention away from the narrow focus on markets and related emphasis on economic incentives.

In particular, there is a very limited understanding of the intangible dimensions of technologies, such as the tacit knowledge, skills, know-how and the organisational and institutional capacities required for technology transfer and diffusion to be sustainable in the long term, which has been greatly overlooked in the literature (de Coninck and Sagar 2015). Expanding our understanding of these aspects requires a more holistic interpretation of technology and a greater emphasis on the broader social and economic implications of technologies.

The following section describes how the individual articles presented in this special issue contribute to the above mentioned knowledge gaps. The concluding section presents a number of crosscutting themes that emerge from the individual articles, suggesting issues for further research. It is our hope that this special issue will not only inform the academic community, but also provide relevant insights to a broader community of stakeholders, including policy makers, climate change negotiators, development aid agencies, multilateral organisations, non-governmental organisation and national planning agencies. 


\section{The articles in this special issue}

The first article presented in the special issue, by Nygaard and Hansen (2015), argues that the definitions of climate technologies, and how the key concept of technology transfer should be understood and operationalized, remain overly diffuse. The article explores the reasons for this conceptual ambiguity by analysing the practical experience from the use a new framework for categorising technologies that was applied by national teams in the first phase of the TNA project implemented in 36 countries by UNEP DTU Partnership (2011-2013). The framework conceptualises a technology as comprising three interrelated elements: a software, orgware and hardware dimension and introduces a fourfold categorisation of technologies according to the types of markets and non-market environments in which they are diffused. The multidimensional conceptualisation of technology introduced in the article introduces a more holistic technology understanding compared to the prevailing hardware focus in the policy discussions and academic research on technology transfer. However, the article also points to the difficulties in operationalising this understanding in practical terms, thereby highlighting the challenges in moving from theory to practice. Secondly, the technology categorisation framework reveals that the barriers and measures to overcome them depend on whether technologies are diffused on market or non-market terms, which contrasts with the prevailing assumption that barriers and measures are generic across technologies. These insights points to the need for greater specificity when describing technologies in policy and academic discussions. Furthermore, the author maintain that there's a need to clarify whether technologies are sets of production system as opposed to discrete operations, and that a technology may be diffused within different markets.

The second article, by Watson et al. (2014), explores the development of capabilities in energy efficient technologies in the cement, coal fired power plant and fuel efficient vehicle industries in China. Specifically, the article analyses the role of domestic and international policy support frameworks and private sector technology transfer in the development of technological capability. Based on in-depth case study research, the article finds that while the Chinese suppliers of energy efficient technologies to the three industries have indeed made progress in technological capability development, there remains a significant gap in technological efficiency and sophistication compared to foreign firms operating at the international technology frontier. The author document how the process of building capabilities has taken place through a mixture of indigenous efforts undertaken by the Chinese firms themselves, e.g. in the form of in-house R\&D, and through linkages with foreign, more advanced technology suppliers, e.g. via license agreements and joint ventures. Their research finds that domestic policies have played an important role in enabling capability development, for example, by enforcing strict energy intensity targets across the three industries, which forced the Chinese suppliers to develop more efficient technologies. The article makes a contribution by challenging the prevailing narrow understanding of technology as hardware, highlighting learning and capability development as crucial (intangible) aspects of technology transfer. It thereby shows the importance of recognising technology transfer as part of broader ongoing process of catching-up and industrial development of firms and industries, rather than a onetime event. In addition, by stressing the importance of domestic policy frameworks, the article shows that technology transfer depends critically on the institutional context in which the technology is diffused. This emphasis on context-specifics, such as enabling frameworks and national policies, is contrasted to the prevailing one-size fits all market-based approach in international policy discussions to enhance technology transfer. 
The third article, by Ockwell et al. (2014), sets out to address the nature of international research and development (R\&D) initiatives, as one form of technology transfer that has been largely overlooked in the literature. The article specifically analyses the conditions under which private and public sector actors engage in $R \& D$ collaboration and how specific developmental needs can be enhanced in collaborative R\&D, while at the same being attractive to firms. A typology of international collaborative R\&D initiatives is presented in the article according to a number of relevant dimensions such as the (public and private) actors involved, temporal scope and funding sources. Given the limited attention the topic has received thus far, this article provides a necessary basis for further studies on international research and development (R\&D) initiatives. By proposing a needs-based approach to technology development, the authors offer an account of how the social and economic developmental goals that generally go unaddressed in global technology markets can be met by international R\&D initiatives. In doing so, they highlight a tension between purely market-based approaches to R\&D collaboration and the fulfilment of broader societal goals. The article identifies the often limited capacity of public agencies and universities in developing countries to participate in or influence international collaborative R\&D in desired directions. This observation highlights the need for designing R\&D initiatives that allow a greater role for public agencies to promote the development of technologies suited for low-income communities that lie outside of established markets and hence are not commercially attractive for mainstream R\&D financing. The article thus illustrates that technology transfer is not only a question of getting the economic incentives right as markets often fail to meet developmental objectives.

The fourth article, by de Coninck and Puig (2015), reviews four sets of multilateral programmes designed to promote the transfer and diffusion of cleaner energy technologies. It does so by analysing the extent to which the different programmes contribute to improving specific functions within technological innovation systems in the target developing countries. More specifically, the analysis presented assesses if and how technology transfer has enhanced the ability of domestic actors (notably businesses, universities, investors, and nongovernmental organisations) and institutional structures (mainly regulatory frameworks and policies) with regard to innovating in low-carbon technologies. The article shows that, while the programmes have indeed contributed to improving the overall innovation systems performance, their impact on improving the ability of actors to perform specific functions differs greatly. It also shows that the programmes have, to varying degrees, enhanced the level of cooperation among different domestic actors, which is an important part of innovation system functioning. The article contributes to a greater understanding of how external programmes influence domestic actors and institutions involved in technology transfer. It thereby clearly shows that technology transfer cannot be understood as a discrete event that can be separated from the institutional conditions in the national and local context. This emphasis on understanding markets as a result of the capacities and interactions among domestic actors and institutions contrasts with the prevailing 'common sense' understanding that technology diffusion can be managed mainly through market-based instruments alone, thus challenging the assumptions of neoliberal thinking.

The fifth article, by Trærup and Stephan (2014), focuses on technologies for adaptation to climate change. More specifically, the authors analyse the local costs and benefits of selected adaptation technologies from the agricultural and water sectors in Lebanon. While limited economic evaluations of the costs and benefits of adaptation technologies have been undertaken, such analyses are needed to provide an evidence-based platform for adjusting agricultural production to climate change impacts, and for understanding how this should be 
evaluated analytically. This is particularly urgent in the agricultural sector, which will be severely affected by climate changes thereby placing an added risk to the livelihoods of many rural populations in developing countries. Based on local-level data collected as part of the country's TNA, the article shows that two specific adaptation technologies (conservation agriculture and rainwater harvesting for irrigation) can be deployed at low cost and with relatively little effort. The article takes an important step to increase the understanding of technology transfer for adaptation technologies, where most studies focus on mitigation technologies. Compared to previous adaptation cost studies, which have used highly aggregated (global) models and estimations, the article further highlights the importance of scaling down the level of analyses to better comprehend the cost and benefits of technologies as applied under local conditions, taking into account key non-market considerations. The article also demonstrates that the transfer and diffusion of adaptation technologies cannot be viewed in a narrow sense, i.e. as the application of a piece of hardware that fulfils a specific adaptation objective (e.g. reducing risks for individual farmers). Rather, adaptation technologies may be viewed as building on top of ongoing (traditional) development planning efforts to achieve broader social and economic developmental goals. This highlights the importance of recognising the intangible aspects of climate technologies, such as the organisational structures and knowledge related to planning in the agricultural sectors.

The sixth and final article presented in this special issue, by Dhar and Marpaung (2014), analyses the technologies chosen in the transport sector by five Asian countries that participated in the first phase of the TNA project. It analyses the criteria for technology prioritisation and also presents a methodology for determining the $\mathrm{CO}_{2}$ reductions from prioritised actions. The analysis reveals that besides social, economic and environmental benefits and the costs of technologies, the evaluation criteria for selecting different technologies also included the characteristics of technologies in terms of reliability, safety, maturity and potential scale of utilisation. As the transport sector is responsible for around $23 \%$ of global GHG emissions, analyses of more efficient and less carbon-intensive transport technologies and modal choices address a priority sector, especially in developing countries, which are expected to be the main contributors to the projected increase in global emissions from the transport sector. Nonmotorized transport, mass transit and technologies that improve vehicle energy efficiency emerged as the three most-preferred technology choices across the participating countries. Developing countries are keen to understand to what extent their technology priorities can be supported by global finances. The NAMA framework provides architecture for this under the UNFCCC, however it emphasises the estimation of $\mathrm{CO}_{2}$ emissions reductions, to the detriment of other co-benefits. The differences in the relative weight assigned to different evaluation criteria by individual countries in their TNAs clearly shows that transport technologies are viewed by the involved government agencies as a multidimensional phenomenon. Countries were also concerned, beyond the costs and benefits of a technology, about the characteristics of a technology (this was the most important criteria in two countries) which may limit the actual scale of diffusion of technologies. Interestingly, the cost parameter was generally weighed equally important in the evaluations undertaken by the individual countries, as compared to various benefit criteria for example related to social, environmental and economic aspects. This points to the limits of the dominant market-based (getting the prices right) approach in order to enhance technology diffusion. The article also contributes to expand the prevailing (narrow) hardware focus in policy and academia by emphasising the deeply entrenched nature of transport technologies in infrastructure investments and city planning. Again this clearly emphasises the intangible organisational and knowledge dimensions of technologies. 


\section{Conclusions and areas for future research}

While the transfer of technologies is high on the agenda in international climate change negotiations, the prevailing discussions reveal a narrow and simplistic understanding of technology and the conditions under which technology transfer occurs. This understanding focuses on technology as a piece of material equipment or hardware and the use of markedbased instruments to promote technology transfer, thus emphasising price mechanisms as the chief concern. This hardware and market discourse has largely spilled over into academic research on technology transfer, which has focused on market instruments as the main driver of technology transfer, most notably the CDM, and the transfer of hardware and the intangible dimensions of technologies, such as codified knowledge in patents and IPRs. A number of crosscutting insights emerge from the articles presented in this special issue that help move beyond this narrow understanding, challenging the prevailing (neoliberal) logic that has come to dominate the international discourse on climate change technology transfer.

The holistic understandings of technology highlighted across the articles in this special issue emphasises the importance of recognising the intangible dimensions of technology, such as the organisational structures and institutional capacities, and hence the highly contextspecific nature of technology development, transfer and diffusion. The academic literature on innovation systems stresses these aspects by emphasizing the complex interaction between actors, political and regulatory conditions and, by extension, the importance of domestic and local institutions as prerequisites for technology transfer. This focus on institutional, political and governance-related issues also highlights the limitations of reducing technology transfer to a question of correcting market failures and getting the prices right. In doing so we can reveal and challenge the extent to which neoliberal ideology (both political and technocratic) has come to dominate both the policy and academic debate about climate technology transfer. By embracing a multidimensional understanding of technology and technology transfer we can appreciate that these issues should not be viewed narrowly as the application of a piece of equipment that fulfils specific mitigation or adaptation goals, but rather as processes deeply imbedded in differing social, economic, and development contexts. This also means that technology transfer should not be understood as a one-off event, but as an ongoing a process that depends upon, and influences, other ongoing country-internal processes.

Future research could focus on analysing in further detail the specific channels through which technology transfer occurs, building upon the understanding that technologies are diffused both through market and non-market mechanisms and channels. A greater understanding is also needed of the specific flow of different resources challenged through technology transfer, such as tacit knowledge and know-how, organisational capacity and financial resources. Building upon the articles in this special issue, such analyses should pay close attention to exploring in greater detail the institutional conditions for technology transfer in specific countries.

\section{References}

Bell M (2012) International technology transfer, innovation capabilities and sustainable directions for development. In: Ockwell D, Mallett A (eds) Low carbon technology transfer: from rhetoric to reality. Routledge, Abingdon, pp 20-50

Byrne R, Smith A, Watson J, Ockwell DG (2012) Pro-poor low carbon development: more than financing technology transfer. In: Ockwell DG, Mallett A (eds) Low-carbon technology transfer: from rhetoric to reality. Routledge, Oxon 
Das K (2011) Technology transfer under the clean development mechanism: an empirical study of 1000 CDM projects (The Governance of Clean Development No. 014). Retrieved from http://tyndall.ac.uk/sites/default/ files/gcd workingpaperarticle014.pdf

de Coninck $\bar{H}$, Puig D (2015) Assessing climate change mitigation technology interventions by international institutions. Clim Chang. doi:10.1007/s10584-015-1344-z (this issue)

de Coninck H, Sagar A (2015) Making sense of policy for climate technology development and transfer. Clim Pol 15(1):1-11

de Coninck HC, Haake F, van der Linden N (2007) Technology transfer in the clean development mechanism. Clim Pol 7(5):444-456

de la Tour A, Glachant M, Ménière Y (2011) Innovation and international technology transfer: the case of the Chinese photovoltaic industry. Energy Policy 39(2):761-770

Dechezleprêtre A, Glachant M, Ménière Y (2007) The north-south transfer of climate-friendly technologies through the clean development mechanism. Energy Policy 36:1273-1283

Dechezleprêtre A, Glachant M, Ménière Y (2008) The clean development mechanism and the international diffusion of technologies: an empirical study. Energy Policy 36(4):1273-1283

Dechezleprêtre A, Glachant M, Haščič I, Johnstone N, Ménière Y (2011) Invention and transfer of climate change-mitigation technologies: a global analysis. Rev Environ Econ Policy 5(1):109-130

Dechezleprêtre A, Glachant M, Ménière Y (2013) What drives the international transfer of climate change mitigation technologies? empirical evidence from patent data. Environ Resour Econ 54(2):161-178

Desgain D, Haselip J (2015) Barriers to the transfer of low-carbon electricity generation technologies in four Latin American countries. Energy Sources B Econ Plan Pol 10(4):348-360

Dhar S, Marpaung COP (2014) Technology priorities for transport in Asia: assessment of economy-wide CO2 emissions reduction for Lebanon. Clim Chang. doi:10.1007/s10584-014-1309-7 (this issue)

Haites E, Duan M, Seres S (2006) Technology transfer by CDM projects. Clim Pol 6(3):327-344

Haščič I, Johnstone N (2011) CDM and international technology transfer: empirical evidence on wind power. Clim Pol 11(6):1303-1314

Haselip J (2010) Content, process and power: towards an analytical framework for public policy and institutional change in less developed countries. University of Reading Geographical Articles Series \# 194

Haum R (2011) Transfer of low-carbon technology under the United Nations Framework Convention on Climate Change: the case of the Global Environment Facility and its market transformation approach in India. Dissertation, University of Sussex

Lema A, Lema R (2013) Technology transfer in the clean development mechanism: insights from wind power. Glob Environ Chang 23:301-313

Levy DL and Egan D (2003) A Neo-Gramscian Approach to Corporate Political Strategy: Conflict and Accommodation in the Climate Change Negotiations. J Manag Stud 40(4):803-829

Murphy K, Kirkman GA, Seres S, Haites E (2013) Technology transfer in the CDM: an updated analysis. Clim Pol 1-19

Nygaard I, Hansen UE (2015) The conceptual and practical challenges to technology categorisation in the preparation of technology needs assessments. Clim Chang. doi:10.1007/s10584-015-1367-5 (this issue)

Ockwell DG, Mallett A (eds) (2012) Low carbon TT: from rhetoric to reality. Routledge, Abingdon

Ockwell DG, Haum R, Mallett A, Watson J (2010) Intellectual property rights and low carbon TT: conflicting discourses of diffusion and development. Glob Environ Chang 20:729-738

Ockwell D, Sagar A, de Coninck H (2014) Collaborative research and development (R\&D) for climate technology transfer and uptake in developing countries: towards a needs driven approach. Clim Chang. doi:10.1007/s10584-014-1123-2 (this issue)

Peck J (2004) Geography and public policy: constructions of neoliberalism. Prog Hum Geogr 28(3):392-405

Peck J, Tickell A (2002) Neo-liberalizing space. Antipode 34:380-404

Pueyo A (2013) Enabling frameworks for low-carbon technology transfer to small emerging economies: analysis of ten case studies in Chile. Energy Policy 53:370-380

Roberts T, Parks B (2006) A climate of injustice: global inequality, north-south politics and climate policy. MIT Press, Cambridge

Schneider M, Holzer A, Hoffmann VH (2008) Understanding the CDM's contribution to technology transfer. Energy Policy 36(8):2930-2938

Seres S, Haites E, Murphy K (2009) Analysis of technology transfer in CDM projects: an update. Energy Policy 37(11):4919-4926

Trærup S, Stephan J (2014) Technologies for adaptation to climate change. Examples from the agricultural and water sectors in Lebanon. Clim Chang. doi:10.1007/s10584-014-1158-4 (this issue)

United Nations Framework Convention on Climate Change (UNFCCC) (1992). Article 4: Commitments. http:// unfccc.int/essential_background/convention/background/items/1362.php

Watson J, Byrne R, Ockwell D, Stua M (2014) Lessons from China: building technological capabilities for low carbon technology transfer and development. Clim Chang. doi:10.1007/s10584-014-1124-1 (this issue) 